\title{
Notes from the Editor-in-Chief
}

Peggy Leatt, $\mathrm{PHD}$

Editor-in-Chief

\section{Quality Councils as Health System Performance and Accountability Mechanisms}

In the LEAd Paper of THis issue, Dobrow, Langer, Angus and Sullivan describe the experiences in general with health councils in Canada and the particular experiences with the implementation of a quality council for cancer care in Ontario. The idea of health quality councils in Ontario is not new. The possibility was first raised by David Naylor, now president of the University of Toronto, in the early 1990s, and in the mid-1990s some early work on quality councils was done for the Ontario government by Jonathan Lomas, current CEO of the Canadian Health Services Research Foundation. The health services restructuring commission of Ontario recommended a Health Quality Council for the province in its report on performance evaluation. None of these early writings seemed to catch on until the reorganization of Cancer Care Ontario (CCO) in 2001 after the Cancer Services Implementation Committee completed its work. Under the expert leadership of Alan Hudson and Terry Sullivan from CCO and the chairmanship of Michael Decter, the Cancer Quality Council of Ontario (CQCO) became a reality. Perhaps it may have been easier to operationalize a council that only deals with one, albeit broad, type of disease - cancer - and a system directed at providing services to that population. Only time will tell.

Mark Dobrow and colleagues begin their paper by describing the experiences of the four different councils that currently exist across Canada: the Health Council of Canada, the Health Quality Council of Alberta, the Saskatchewan Health Quality Council and the CQCO. The mandates and missions of these organizations are contrasted, along with their roles and responsibilities. The council membership and staff are compared, and implications are drawn about how each council operates. The authors then proceed to describe the workings of $\mathrm{CQCO}$ in further detail. The council had an initial agenda of four components: benchmarking on the current state of quality in Ontario's cancer care system, sponsoring signature events to draw attention to important issues, developing a concise set of quality indicators and developing a program of health services research. Over the first three years of its life, the council appears to have made very good progress in all four areas. 
At the conclusion of their paper, the authors raise the critical question of whether quality councils actually achieve an improvement in the quality of services provided to patients. Certainly they appear to focus attention around important issues as well as providing data and coordination of efforts. Perhaps these modest results are all we can expect at this stage.

The discussion of the roles of quality councils is enriched by the expert commentators on the lead paper. We begin with Bruce Barraclough, who provides the Australian perspective. Australia was one of the first countries to identify the extent of its patient safety issues through a study in 1995. Several precursor committees were established, leading to the formation of the Australian Council for Safety and Quality of Health Care in 2000. The Council was allocated $\$ 55$ million over a six-year term to focus on areas perceived to cause the greatest harm such as medication errors, infections, use of blood products, patient falls and pressure ulcers. Most recently the Council has evolved into the Australian Commission on Quality and Safety in Health Care.

Enrique Ruelas, Undersecretary of Health for Quality and Innovation in the Secretary of Health of Mexico, provides a refreshing perspective on how to address issues of quality. On the basis of his experiences in Mexico, he describes the establishment of Citizen Endorsement Groups that are volunteer, non-health professional groups that examine the "responsiveness" of the health system. To date there are almost 800 of these groups in existence.

Benjamin T.B. Chan, Marlene Smadu and J. Stewart McMillan describe the experiences of the Health Quality Council (HQC) of Saskatchewan. HQC has a mandate to improve the quality of care and the caring experience through the use of best practices. Of the four councils in Canada it is clearly the largest, conducting much of the research internally and taking a quality improvement approach. HQC has been able to negotiate access to comprehensive data on Saskatchewan health, as well as conducting primary data collection to track indicators of quality and adverse events. HQC also maintains Innovation Fund that supports small-scale, exploratory quality improvement projects. The authors note one drawback: physicians operate outside the Regional Health Authority structure and therefore are not included in much of the database.

Carolyn Clancy, Director, Agency for Healthcare Research and Quality, Department of Health and Human Services, has the potential to be very influential in enhancing quality improvement. In 2006 the Agency published the third annual report on quality and disparities in care associated with race, ethnicity, income, education and other characteristics. She points out the importance of payers in monitoring 
and improving quality. She describes the role of the National Quality Forum in developing measures of quality and monitoring quality on an ongoing basis. She notes a new Institute of Medicine report, Performance Measurement: Accelerating Improvement (2006).

J. Michael Plumb and John W.F. Cowell of the Health Quality Council of Alberta (HQCA) emphasize that it is important for a council to be sufficiently empowered to do its work. They describe the multilevel measurement strategy used in Alberta to set priorities, to establish an imperative for action and to assess progress. The authors report positively on the Council's efforts in measurement and reporting and point out the necessity of tailoring reports to the needs of different audiences. They stress that public reporting on quality is part of a continuum of communications to better inform all stakeholders including users, the community and providers. Plumb and Cowell make strong distinctions between the quality improvement strategies used by councils and the recent trend to focus on pay-for-performance strategies that provide incentives for providers to improve performance on cost and quality.

In conclusion, while the jury is still out on the effectiveness of health quality councils, it seems clear that the very existence of a council can draw attention to issues of quality monitoring. That in itself would seem like a worthwhile goal at this early stage. It will be important to evaluate the range of activities that councils engage in and the communications networks they are able to establish. Even over the long term, it may be difficult to attribute improvements to the work of a council. The strongest links may be most discernible when very specific patient populations and precise and measurable services are identified. 